\title{
Pengukur Tingkat Kekeruhan Keasaman Dan Suhu Air Menggunakan Mikrokontroler Atmega328p Berbasis Android
}

\author{
Andre Prayoga ${ }^{1}$, Yudi Ramdhani ${ }^{2}$, Ade Mubarok ${ }^{3}$, Salman Topiq ${ }^{4}$ \\ ${ }^{1}$ Universitas BSI \\ e-mail: dre.prayoga@gmail.com \\ ${ }^{2}$ Universitas BSI \\ e-mail: yudi.yrm@bsi.ac.id \\ ${ }^{3}$ Universitas BSI \\ e-mail: ade.amb@bsi.ac.id \\ ${ }^{4}$ Universitas BSI \\ e-mail: salman.ssc@bsi.ac.id
}

\begin{abstract}
Abstrak
Dalam perancangan alat pendeteksi kualtias air sebelumnya, maka dapat disimpulkan terdapat beberapa peracangangan alat yang belum efektif dan efisien dari segi komponen sensor yang digunakan, parameter yang diukur dan cara data ditampilkan, beberapa masih menggunakan gabungan sensor dan penampil data yaitu LCD (liquid crystal diode). Penulis membuat sistem alat pendeteksi kualitas air yang berfokus pada parameter kekeruhan, keasaman, dan suhu air dengan menggunakan sensor SEN0189, Sensor PH, DS18B20 serta penampil data yang menggunakan smartphone Android. Cara kerja alat yaitu parameter kekeruhan air dideteksi dengan sensor Turbidity SEN0189 yang memanfaatkan transimisi chaya dan hamburan partikel, nilai keasaman dan basa air diukur menggunakan sensor $\mathrm{PH}$ dengan batas pengukuran $0-14 \mathrm{PH}$, nilai suhu air diukur menggunakan sensor DS18B20. Prameterparameter air yang dikelolah oleh setiap sensor akan diproses melalui mikrokontroler IC ATmega328p dengan basis pemprograman menggunakan Arduino IDE, untuk menghubungkan mikrokontroler dengan smartphone Android, maka modul bluetooth dipasang pada mikrokontroler. Aplikasi android yang digunakan untuk menampilkan data dari alat ukur kekeruhan, keasaman, dan suhu air ke smartphone dibuat di App Inventor. Pengukuran dilakukan terhadap empat sampel diantaranya air minum isi ulang, air mineral kemasan, air hujan, dan air ledeng. Tingkat kekeruhan dari pengukuran keempat sampel tersebut memiliki nilai rata-rata sebesar 1256,34 , nilai tingkat keasaman sebesar $9-10 \mathrm{PH}$, dan rata-rata nilai suhu sebesar $27,6^{0} \mathrm{C}$.
\end{abstract}

Kata Kunci : Sensor PH, DS18B20, SEN0189, ATmega328p, Android

\begin{abstract}
In design the measurement instrument of water quality before, that can concluded there are some designs which not effetive and eficient from the sensor components used, parameters was measured and how the data was displayed, some measuring instrument water quality detection still use some combined sensors and the data viewer is LCD (liquid crystal diode). The writer creates the instrument system to detect water quality which focus on water's turbidity, acid, and temperature using sensor SEN0189, Sensor PH, DS18B20 and the data viewer which using Android smartphone. How the measuring instrument works is the water's turbidity parameter detected by SEN0189 Trubidity sensor which use light transmition and scattering particles, the value of water's acid and bases measured by $\mathrm{PH}$ sensor with top measuring about $125^{0}$ celcius. The parameters which measured by each sensor will processed using microcontroller IC ATmega328p with Arduino IDE program, to connecting microcontroller to Android smartphone, then blouetooth modul is installed on microcontroller. The Android aplication which used to display data from the measuring instrument of water's turubidity, acid,
\end{abstract}


and temperature to smartphone which made on App Inventor aplication. Level of turbidity from four water's sampelshave avarage value is 1256,34 , level of water's acid have range value about $9-10 \mathrm{PH}$, and level of temperature have avarage value about $27,6^{\circ} \mathrm{C}$.

\section{Keyword : Sensor PH, DS18B20, SEN0189, ATmega328p, Android}

\section{Pendahuluan}

Air merupakan zat cair yang dinamis bergerak dan mengalir melalui siklus hidrologi yang abadi (Faisal, 2012). Manfaat air sangatlah banyak bagi manusia, hewan dan tumbuhan. Manfaat air dalam kegiatan manusia diantaranya air digunakan untuk minum, masak, mencuci, dan kegiatan bersih-bersih. Air juga diperlukan untuk kegiatan pertanian yaitu irigasi lahan pertanian, dan juga digunakan untuk lahan perternakan seperti tambak, kolam, keramba apung (Musriyah, 2016). Pengelolahan kualitas air dan pengendalian pencemaran air yang disusun berbasis kelas mutu air, diantaranya : Kelas satu, air yang peruntukannya dapat digunakan untuk air minum. Kelas dua, air yang peruntukannya dapat digunakan untuk prasarana/sarana rekreasi air, pembudidayaan ikan air tawar, peternakan, dan air untuk mengairi tanaman (Yusuf, 2014).

Sedikit air yang terdapat dari sumber alam dapat diminum oleh manusia, tetapi terdapat resiko jika air ini telah tercemar oleh bakteri misalnya Escherichia coli atau zat-zat berbahaya. Walapun bakteri dapat dibunuh dengan memasak air hingga $100^{\circ} \mathrm{C}$, tetapi banyak zat berbahaya, terutama logam, tidak dapat dihilangkan dengan cara mendidihkan air. Syarat-syarat air minum, yaitu tidak berbau, tidak berasa, kekeruhan tidak boleh melebihi 5 NTU (Nephelometric Turbidity Unit), tidak berwarna, tidak mengandung logam berat, dan tidak mengandung bakteri patogen, bakteri patogen dapat membentuk toksin atau racun setelah periode laten yang singkat yaitu beberapa jam, dapat menyebabkan muntaber (Beni, 2010). Air dapat dimanfaatkan sebagai sumber irigasi untuk pertanian, syarat-syarat air yang dapat digunakan untuk irigasi, jika mengambil dari parameter pada penelitian yaitu memiliki temperatur suhu diantara $18^{\circ} \mathrm{C}-35^{\circ} \mathrm{C}$, dan memiliki tingkat keasaman air diantara $6-8,5 \mathrm{PH}$. Hal tersebut dapat mempengaruhi pertumbuhan padi di sawah (Yusuf, 2014).

Untuk mengetahui tingkat kualitas air, maka dibuatlah alat yang dapat mengukur parameter-parameter air, terutama tingkat kekeruhan, keasaman, dan suhu dalam air. Perancangan alat sebelumnya berfokus pada pengukuran tingkat keasaman, suhu, kekeruhan, dan jumlah padatan terlalarut. Sensor yang digunakan dalam perancangan alat tersebut adalah sensor PH dan LM35 (Amani \& Prawiroredjo, 2016). Selanjutnya terdapat perancangan alat yang berfokus hanya pada perhitungan tingkat kekeruhan air, jenis sensor yang digunakan dalam perancangan alat tersebut adalah Fotodiode TSL250 (Maemunnur \& Wiranto, 2016). Terdapat juga perancangan alat yang berfokus hanya pada perhitungan tingkat keasaman air dan sensor yang digunakan adalah sensor PH (Ihsanto \& Hidayat, 2014).

Dalam perancangan alat pendeteksi kualitas air sebelumnya, maka dapat disimpulkan terdapat beberapa perancangan alat yang belum efektif dan efisien dari segi komponen sensor yang digunakan dan cara data ditampilkan, beberapa perancangan alat pendeteksi kualitas air masih menggunakan beberapa gabungan sensor untuk menghitung satu parameter air, dan untuk menampilkan data yang diolah mikrokontroler masih menggunakan komponen LCD. Untuk itu penulis membuat sistem alat pendeteksi kualitas air yang berfokus pada parameter kekeruhan, keasaman, dan suhu air dengan menggunakan sensor dan penampil data yang lebih efisien dari pembuatan alat pendeteksi kualitas air sebelumnya. Peracangan alat yang dibuat penulis yaitu dengan menggabungkan beberapa perancangan alat dari penelitian sebelumnya dan mengganti beberapa komponen yang digunakan. sensor yang digunakan dalam peracangan alat yaitu Turbidity SEN0189 untuk mengukur tingkat kekeruhan air, memiliki batas pengoperasian temperatur $5^{\circ} \mathrm{C}-90^{\circ} \mathrm{C}$, sensor PH SEN0161 untuk mengukur tingkat keasaman air, dengan batas pengukuran $0-14 \mathrm{PH}$, dan sensor DS18B20 untuk mengukur tingkat suhu air yang memiliki batas pengukuran maksimal sebesar $125^{\circ} \mathrm{C}$. Untuk penampil data, 
komponen yang digunakan yaitu smartphone dengan koneksi bluetooth $\mathrm{HC}$ 05 sebagai perantara dengan alat ukur tingkat kekeruhan, keasaman dan suhu air.

\section{Metode Penelitian}

\section{Perancangan Dan Pembuatan}

Didalam flowchart hardware

dijelaskan bagaimana ketika alat ukur kekeruhan, keasaman, dan suhu air berkerja hal yang pertama dilakukan adalah input catu daya, pada proses ini besar catu daya yang dibutuhkan untuk menjalankan alat ukur kekeruhan, keasaman, dan suhu air yaitu sebesar 6v-9v (volt), kemudian akan dilakukan pengambilan data menggunakan sensor. Untuk melakukan pembacaan dari sensor dibutuhkan beberpa proses yang dimasukan ke dalam program, dapat dilihat pada gambar 1 . Proses pengambilan data dilkakukan, data akan dikirimkan melalui module bluetooth ke smartphone bersistem operasi Android. Kemudian hasil data yang dikirimkan melalui alat ukur kekeruhan, keasaman, dan suhu air akan ditampilkan ke dalam aplikasi yang telah terinstal pada smartphone.

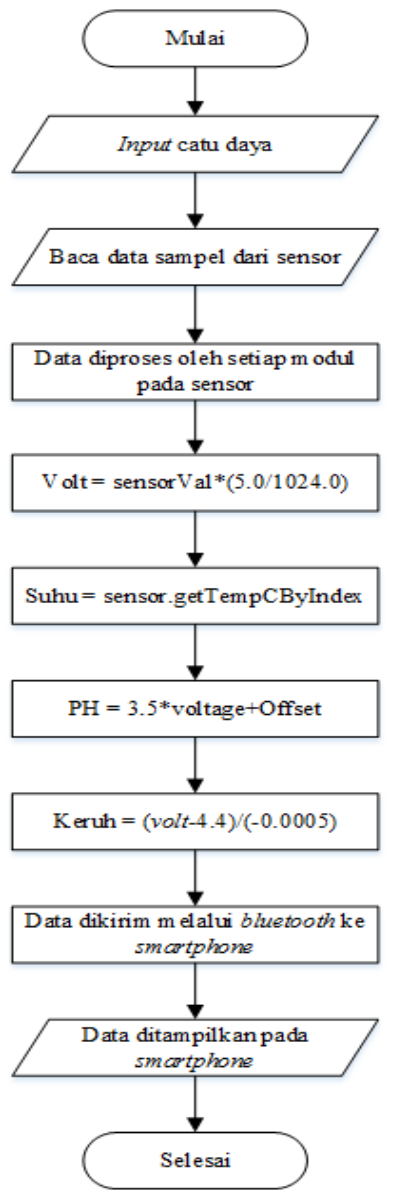

\section{Hasil dan Pembahasan}

Pada tahap ini dijelaskan terdapat beberapa sensor yang diproses oleh block sistem minimum ATmega328p. Block sensor $\mathrm{PH}$ berfungsi untuk mendapatkan data tingkat keasaman dan basa dari zat cair yang dianalisa dengan satuan $\mathrm{PH}$, block sensor $\mathrm{PH}$ terdiri dari probe $\mathrm{PH}$ dan module sensor $\mathrm{PH}$, tegangan maksimal yang dibutuhkan dari block $\mathrm{PH}$ yaitu sebesar 5v. Block sensor SEN0189 merupakan block yang berfungsi untuk mendapatkan data tingakat kekeruhan dari zat cair yang diteliti, data yang dihasilkan berupa perubahan tegangan sesuai dengan kondisi zat cair. Tegangan yang dibutuhkan pada block sensor SEN0189 yaitu sebesar $5 \mathrm{v}$ dan tegangan keluaran yaitu sebesar 4.5v. Block sensor SEN0189 terdiri dari module sensor dan sensor SEN0189. Sedangkan block sensor DS18B20 merupakan block yang berfungsi untuk mendapatkan data suhu zat cair dalam satuan celcius, tegangan yang dibutuhkan block sensor DS18B20 yaitu sebesar 3.0v $5.5 \mathrm{v}$. Block sensor DS18B20 terdiri dari module sensor dan sensor DS18B20. Data yang didapat dari ketiga block sensor tersebut akan diproses oleh block sistem minimum ATmega328p dan dikirim melalui jalur komunikasi nirkabel pada block bluetooth HC-05 ke smartphone Android.

\subsection{Rangkaian Keseluruhan}

Dijelaskan pada gambar 2 merupakan rangkaian keseluruhan proses pembuatan alat pengukur tingkat kekeruhan keasaman dan suhu air. Rangkaian keseluruhan merupakan gabungan dari rangkaian input, rangkaian mikrokontroler, rangkaian output, dan rangkaian catu daya. Berikut merupakan gambar dari rangkaian keseluruhan alat ukur kekeruhan, keasaman dan suhu air.

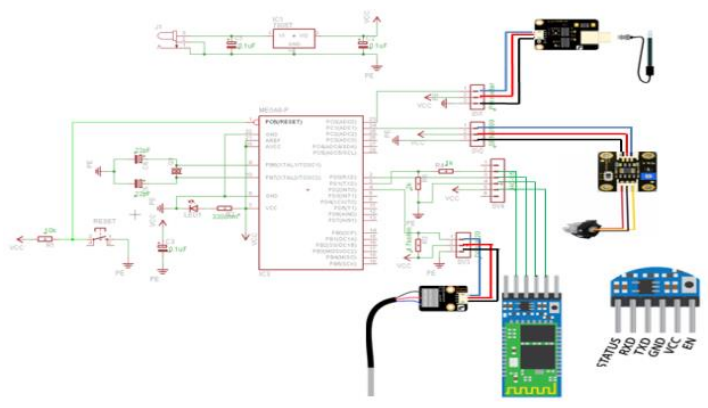

Gambar 2. Rangkaian Keseluruhan

Gambar 1. Flowchart Program Hardware 


\subsection{Perancangan Program Software} Didalam flowchart software dijelaskan bagaimana ketika program pertama dijalankan, pengguna akan diminta agar smartphone terkoneksi dengan alamat bluetooth dari alat ukur kekeruhan, keasaman, dan suhu terlebih dahulu. Jika smartphone pengguna tidak terkoneksi ke alamat bluetooth dari alat ukur kekeruhan, keasaman, dan suhu air dengan benar, maka alur proses akan dinyatakan selesai, dan data tidak dapat ditampilkan. Jika smartphone pengguna dapat terkoneksi ke alamat bluetooth dari alat ukur kekeruhan, keasaman, dan suhu air dengan benar, maka akan dilakukan proses pengambilan data berdasarkan urutan dari index masingmasing parameter. Setelah proses pengambilan data dilakukan berdasarkan index, data akan ditampilkan pada kolom dalam aplikasi android sesuai dengan label parameter masing-masing. Dapat dilihat pada gambar 3 .

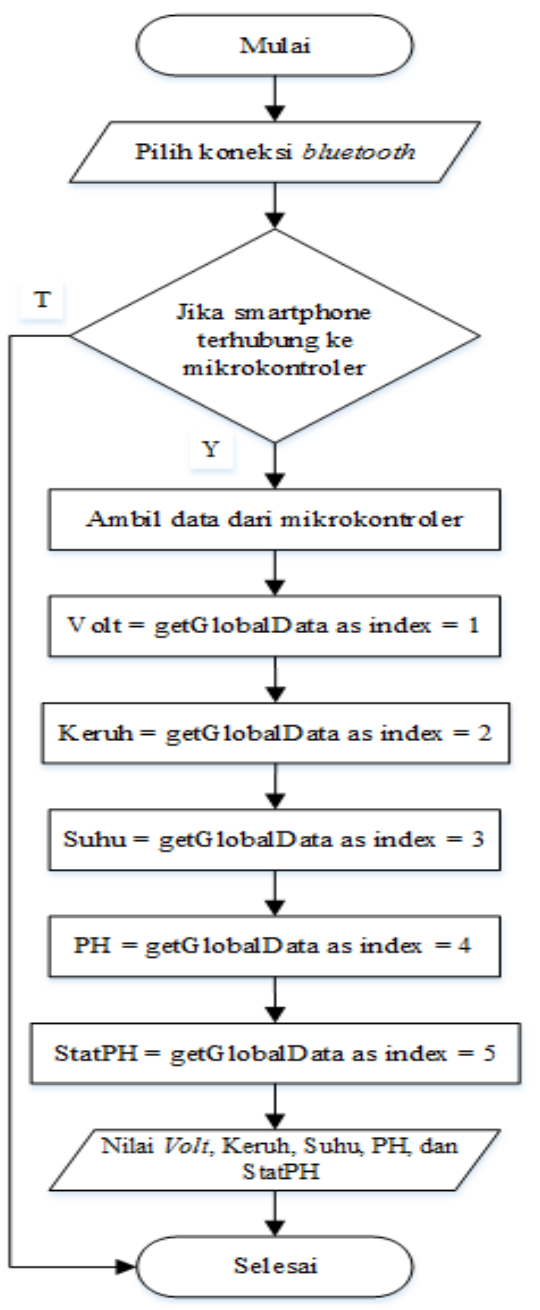

Gambar 3. Flowchart Program Software

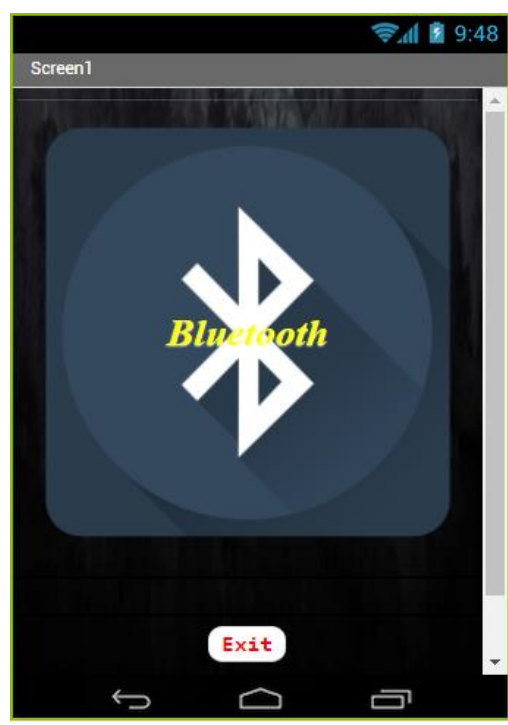

Gambar 4. Tampilan Pertama Aplikasi Android

Pada gambar 4 merupakan tampilan ketika aplikasi Android dibuka, didalam tampilan tersebut pengguna akan melakukan pairing bluetooth terlebih dahulu dengan menekan icon bluetooth, kemudian akan muncul tampilan daftar nama alamat bluetooth dari alat ukur kekeruhan, keasaman, dan suhu air. Setelah nama alamt bluetooth dipilih, secara otomatis data yang telah diproses dari alat ukur kekeruhan, keasaman, dan suhu air dikrimkan ke aplikasi Android, kolom dari masing-masing paramater yang ada pada gambar 5 akan terisi sesuai perhitungan.

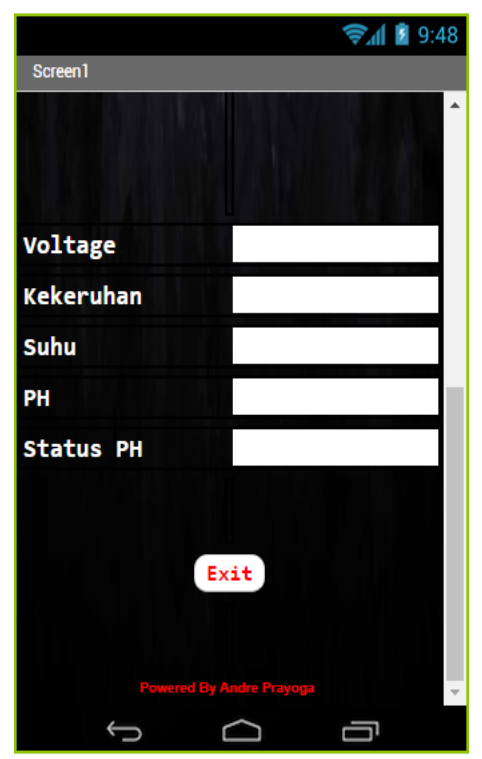

Gambar 5. Tampilan Utama Aplikasi Android 


\section{Kesimpulan}

Dalam penulisan skripsi Alat Ukur Tingkat Kekeruhan, Keasaman, Dan Suhu Air Menggunakan Mikrokontroler ATmega328p Berbasis Android yang dilakukan oleh penulis, dapat diambil kesimpulan, diantaranya alat ukur yang telah dibuat dapat menentukan kualitas air dari parameter kekeruhan, keasaman, dan suhu air. Dengan menggunakan smartphone bersistem Android sebagai penampil data yang dihubungkan ke mikrokontroler melalui koneksi bluetooth, pengukuran menjadi lebih efisien. Alat ukur yang telah dibuat juga dapat digunakan dalam kehidupan sehari-hari. Tingkat pengukuran $\mathrm{PH}$ pada sampel air hujan di daerah Antapani Bandung tergolong basa dengan nilai $\mathrm{PH}$ sebesar 9.70. perubahan nilai kekeruhan dan suhu sangat berpengaruh pada tempat dilakukannya proses pengukuran, sensor kekeruhan yaitu sensor SEN0189 sangat sensitif terhadap cahanya disekitarnya, dan perubahan nilai suhu yang didapat dari sensor suhu yaitu DS18B20 dapat dipengaruhi dari keadaan suhu di lokasi tempat pengukuran.

\section{Referensi}

Abidin, H. (2013, Januari 17). Definisi Program Komputer. Dipetik Mei 18, 2017, dari penelitianhukum.org:

https://penelitihukum.org/tag/def inisi-program-komputer/

Ali, U. (2002, Juni 05). Kumpulan Pakar. Dipetik 10 11, 2016, dari Kumpulan Pengertian Menurut Para Pakar: http://www.pengertianpakar.com /2015/06/pengertian-metodepenelitian-jenis-dancontohnya.html

Amani, F., \& Prawiroredjo, K. (2016). ALAT UKUR KUALITAS AIR MINUM DENGAN PARAMETER $\mathrm{PH}, \quad$ SUHU, TINGKAT KEKERUHAN, DAN JUMLAH PADATAN TERLARUT. JETri, $49-62$.

azhar, a. (2011, November 23). Sekilas Mengenai

Bahasa
Pemrograman $C$ dan $C++$. Dipetik Mei 18, 2017, dari informatika sesuatu [just another students.uii.ac.id] Blogs weblog:

http://azrinaazhar.students.uii.ac .id/2011/11/23/sekilas-

mengenai-bahasa-

pemrograman-c-dan-c/

Beni, M. D. (2010, November 29). Kriteria Air Layak Minum. Dipetik April 18, 2017, dari Media Center Kendedes Dinas Kominfo Kota Malang: http://mediacenter.malangkota.g o.id/2010/11/kriteria-air-layakminum/\#axzz4ecTtAUZb

Cangeloso, S. (2012). LED Lighting. United States America: O'Reilly Media, Inc,. 1005 Gravenstein Highway North, Sabastopol, CA 95472.

Chandrappa, \& Dharmanna. (2017). Design and Development of loT Device to Measure Quality of Water. I.J. Modern Education and Computer Scient, 50-56.

Dobkin, D. (2013). THE RF IN RFID. USA: Elsevier Inc.

Effendi, I. M. (2016, Juni 14). Pengedalian Pencemaran Air Dalam Perlindungan Dan Pengelolaan Lingkungan Hidup. Dipetik Mei 28, 2017, dari Sistem Informasi Lingkungan Hidup:

http://kepbabel.silh.menlh.go.id/ $428 /$

Faisal, A. (2012, September 27). Pengertian Air dan Syaratsyarat Air Bersih. Dipetik April 18, 2017, dari SHARE IT Blog Mahasiswa Universitas Brawijaya: http://blog.ub.ac.id/alfianfaisal/2 012/09/27/pengertian-air-dansyarat-syarat-air-bersih/ 
Ginting, F., \& Mamahit, D. (2013). Perancangan Alat Ukur Kekeruhan Air Menggunakan Light Dependent Resistor Berbasis Mikrokontroler Atmega 8535. E-Journal Teknik Elektro dan Komputer, 1 - 7.

Insanto, E., \& Hidayat, S. (2014). RANCANG BANGUN SISTEM PENGUKURAN Ph METER DENGAN MENGGUNAKAN MIKROKONTROLLER

ARDUINO UNO. Jurnal Teknik Elektro, Universitas Mercu Buana, 139 - 146.

Intania. (2012). Panduang Paling Lengkap dan Mendetail Tentang Andorid. Jakarta: Kuncikom Jakarta ISBN : 978-602-938020-0.

Irvananda. (2014, September 15). Flowchart dan DFD. Dipetik Mei 18, 2017, dari Sistem Informasi: http://irvananda.blog.binusian.or g/2014/09/15/flowchart-dfd/

Ismail, R. (2016, Mei 1). PH meter : Alat Pengukur Tingkat Keasaman Sampel Dalam Fase Larutan Secara Kuantitatif. Dipetik Mei 18, 2017, dari Rohmatchemistry's blog (knowladge, learning, and sharing):

http://rohmatchemistry.staff.ipb. ac.id/2016/05/01/ph-meter-alatpengukur-tingkat-keasamansampel-dalam-fase-larutansecara-kuantitatif/

Johans. (2013, Oktober 8). Komponen Aktif dan Pasif Elektronika. Dipetik Mei 17, 2017, dari Johan.Students Resoft: http://johans.student.akademitel kom.ac.id/index.php/2013/10/08 /elektronika/

Maemunnur, A. F., \& Wiranto, G. (2016). RANCANG BANGUN
SISTEM ALAT UKUR TURBIDITY UNTUK ANALISIS KUALITAS AIR BERBASIS ARDUINO. Fibusi (JoF), Vol 4 No 1. 1 April 2016, 1 - 8.

Mirelsol. (2014, Juni 16). Hydroponics in the Sassi of Matera with Arduino. Dipetik Mei 18, 2017, dari Mirelsol's technical corner: http://tech.mirelsol.org/doku.php /projects/hydroponics_sassi_ma tera_1/start

Musriyah. (2016, Febuari 11). Manfaat Air Bagi Manusia, Hewan dan Tanaman. Dipetik April 18, 2017, dari Website Resmi Pemerintah:

http://www.pekalongankab.go.id /informasi/artikel/kesehatan/797 3-manfaat-air-bagi-manusia,hewan-dan-tanaman.html

Platt, C. (2013). Encyclopedia of Electronic Component. United States of America: O'Reilly Media, Inc., 1005 Gravenstein Higway North, Sabastopol, CA 95472.

Rasjid, E. F. (2014, 09 September). Android : Sistem Operasi Pada Smartphone. Dipetik Mei 28, 2017, dari UBAYA (Universitas Surabaya):

http://www.ubaya.ac.id/2014/co ntent/articles_detail/7/Android--

Sistem-Operasi-pada-

Smartphone.html

rizkia. (2015, Juli 9). Temperature Sensor. Dipetik Mei 18, 2017, dari Rizkia's blog [Just another Telkom University Official Blog Sites]:

http://rizkia.staff.telkomuniversit y.ac.id/temperature-sensor/

Santosa, H. (2012, Juni 27). Memilih Komponen Untuk Minimum System AVR. Dipetik Mei 17, 2017, dari Hardi Santosa: 
http://hardi-

santosa.blog.ugm.ac.id/2012/06 /27/memilih-komponen-untuk-

minimum-system-avr-2/

Siltri, D. M., \& Kamus, Z. (2015). PEMBUATAN ALAT UKUR SALINITAS DAN KEKERUHAN AIR MENGGUNAKAN SENSOR ELEKTRODA DAN LDR. Jurnal Saintek Vol. VII No.2, 126 - 139.

Siswoyo, B. (2012, Juni 20). Belajar Arduino: pengantar. Dipetik Mei 18, 2017, dari Bambang Siswoyo:

http://bsiswoyo.lecture.ub.ac.id/ 2012/06/belajar-arduinopengantar/

Siwindarto, P. (2012, November 11). Sensor. Dipetik Mei 28, 2017, dari Sensors, Instrumentation, Electronics:

http://instrumentasi.lecture.ub.a c.id/tag/sensor/

Vodovozov, V. (2010). Intruduction to Electronic Engineering. Estonia: Valery Vodovozov.

Wahyudi, E. (2015, November 25). Aplikasi Andorid Tanpa Coding. Dipetik Mei 28, 2017, dari Teknik Informatika Universitas Ciputra Surabaya: http://informatika.uc.ac.id/2015/ 11/aplikasi-android-tanpacoding/

Wibirama, S. (2013, April 30). Bagaimana Membuat Studi Pustaka yang Baik. Dipetik April 24, 2017, dari Dr. Sunu Wibirama GoodScience, LLC | Scientific Writing and Research Coarching:

http://wibirama.staff.ugm.ac.id/2

013/04/30/sunu-wibirama-

bagaimana-membuat-studi-

pustaka-yang-baik/
Yusuf, I. (2014). Kajian Kriteria Mutu Air Irigasi. Jurnal Irigasi - Vol.9, No.1, Mei 2014, 1 - 15. 